\title{
Evaluation of Screen Printing using Cochineal Natural Dye
}

\author{
Sudipta Dasgupta and Subhas Ghosh* \\ Eastern Michigan University, USA \\ *Corresponding author: Subhas Ghosh, Eastern Michigan University, Ypsilanti, Michigan, USA \\ submission: 海 April 19, 2018; Published: 湝 May 23, 2018
}

\begin{abstract}
Recently a great interest has been developed in the use of natural dyes for fashion apparel textiles which arises from the restrictions on the effluent to be released from the dye houses to reduce pollution. Wash colorfastness has been a continuing problem in the use of natural dyes. This study addresses this issue by investigating screen printing on cotton fabric using Cochineal natural dye in the presence of stannous chloride as the mordant. It was found that, the dye recipe using $6 \%$ Cochineal pigment in water-based solvent, where the fabric was soaked in the heated stannous chloride mordant for an hour and cured at $160 \mathrm{oC}$ for 3 minutes, produced the best screen print on $100 \%$ cotton fabric in terms of appearance and color wash fastness.
\end{abstract}

\section{Introduction}

With the recent emphasis on sustainability and environmental responsibility, more and more natural and organic products are being used in every facet of life. The same revolution can be observed in the textile and fashion industry. Natural dye is obtained from nature like plants, animals or minerals. Natural dye is sometimes preferred over synthetic dye because of its environment friendly and nontoxic nature. But natural dye has limitations; one such limitation is poor colorfastness to laundering. So, there is a need of developing methods of natural dyeing that gives an acceptable performance in terms of appearance and colorfastness. Mostly all of the natural dyes require the use of a mordant or a thickening agent polymer to fix them on to the textile substrate. This study investigates a natural dye recipe made of Cochineal pigment on $100 \%$ cotton fabric that gives the best performance in terms of color appearance and fastness using the screen printing technique.

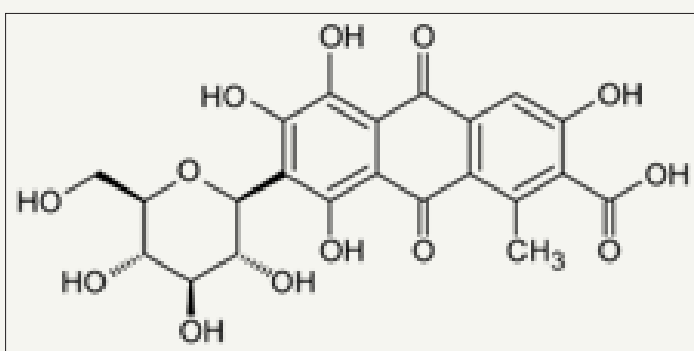

Figure 1: The chemical structure of Carminic acid [1].

Cochineal is a type of natural pigment which is obtained from a scaly insect of the same name mostly found in cacti of Mexico and South America. It is scraped off, dried and crushed to make the Cochineal extract that produces red or purple color dyes [1]. It contains Carminic acid as seen in the chemical structure in Figure1, which produces the color. Screen printing gained popularity because it is economical and easy to apply. Also, it uses less dye and achieves the same product appeal for lower cost than by weaving a design.

Gabriela et al. [2] used K/S analysis of the dyed fabric to determine the effect of different mordant with cochineal dye. They found that mordant concentration is highly responsible for color fixation of Cochineal dye where pre-mordanting helped them to achieve the best colorfastness. Also, Eva et al. [3] premixed guar gum with a small amount of an industrial protease to eliminate the 'dotting effect' in direct textile printing. Akemi Yasukawa et al. [4] used natural blackcurrants with metallic mordant containing $\mathrm{Mg}$, $\mathrm{Fe}$ and $\mathrm{Cu}$ to dye silk and cotton fabrics where cotton had a lower wash fastness than silk. Sudha Babel \& Rupali Gupta [5] used natural thickener like Cassia seed gum and Mango seed gum using Butea monosperma flower dye, to screen print on silk fabric with the help of Fe \& $\mathrm{Cu}$ mordants. In our study, the printing ink was mixed with a water based thickening agent containing Vinyl resin as the binder for better print appearance. Stannous chloride mordant was used for better fastness of the print. Dawn et al. [6] used extracts from dried leaves and bark of eucalyptus to screen print on lyocell fabric both with and without mordant using alum, calcium carbonate, soya milk and tannic acid as the mordants. In this case, the printed fabric without mordant unexpectedly gave better color fastness to wash, light and rubbing than the printed fabric with mordant. However, no definite explanation was provided for this occurrence. 
Print performance also depends on the curing process. Mohammad et al. [7] screen printed the PLA fabrics and thermally cured them at different temperatures ranging from 120 oC to150 oC for 3 minutes to 5 minutes. They found that the prints were cured better at a higher temperature as the higher concentration of binder and pigment in printing paste generally needs a higher fixation temperature and time to cross-link and bond with the PLA fibers [8].

\section{Method and Materials}

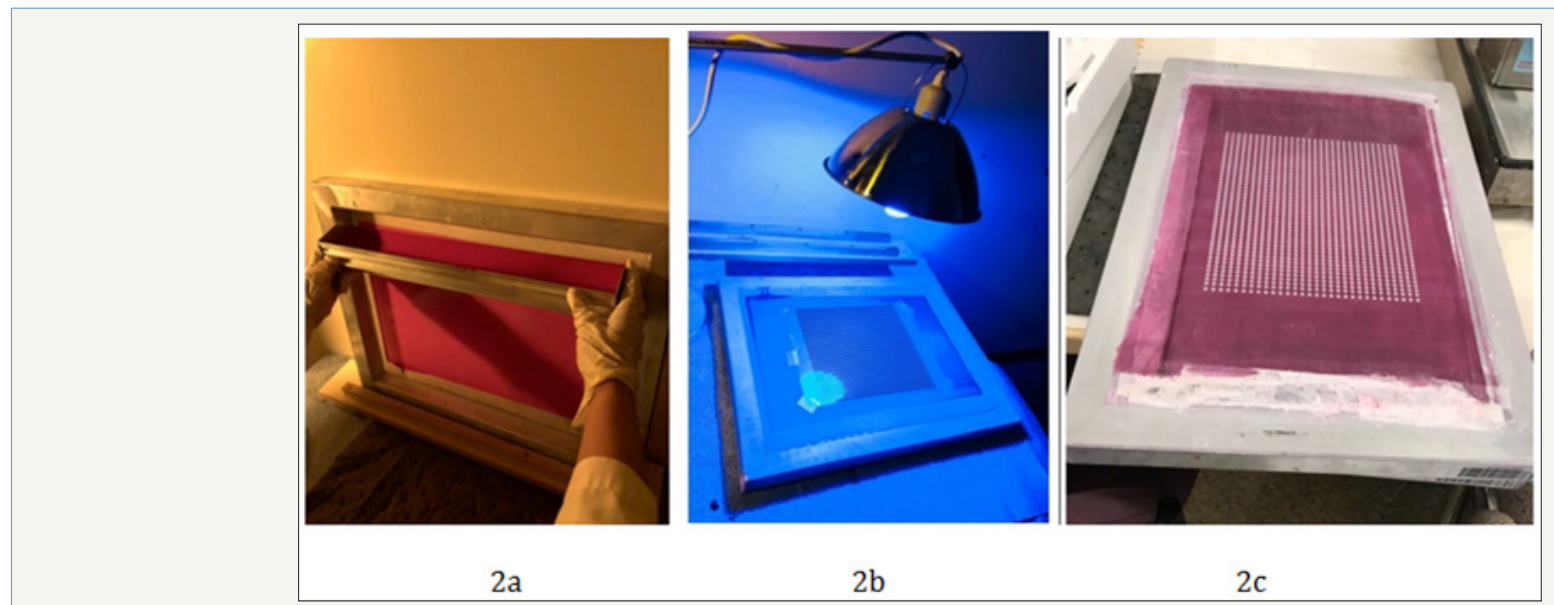

Figure 2a: Application of emulsion to the screen by a scoop coater.

Figure 2b: The process of screen exposing.

Figure 2c: The ready screen after washing away the emulsion.

The screen preparation was performed by using a photo curing method. At first, the screen was coated with the emulsion and kept for drying for 2 hours as shown in Figure 2a. In the meantime, the design was printed on a transparency in opaque black ink. Then the design was taped on the dry screen and exposed under 500W UV light for 12 minutes as shown in Figure $2 \mathrm{~b}$. After the screen was burnt, it was washed by water spray to finally get the prepared screen in the form of a stencil as shown in Figure 2c. The whole process of screen preparation was done in a dark room using a bug safe light.

\section{Screen emulsion chemistry}

The emulsion used in the study is a colloidal solution of polyvinyl acetate mixed with a diazo photosensitizer. When the emulsion on screen was exposed under the UV light, the diazo got activated and made cross linking with the polyvinyl acetate making the emulsion hard as shown in Figure 3. But the print areas covered by the black print of the design, blocked the light, therefore preventing the photo curing process. So, the emulsion which was not cured remained soft and washed off with water producing the screen stencil.

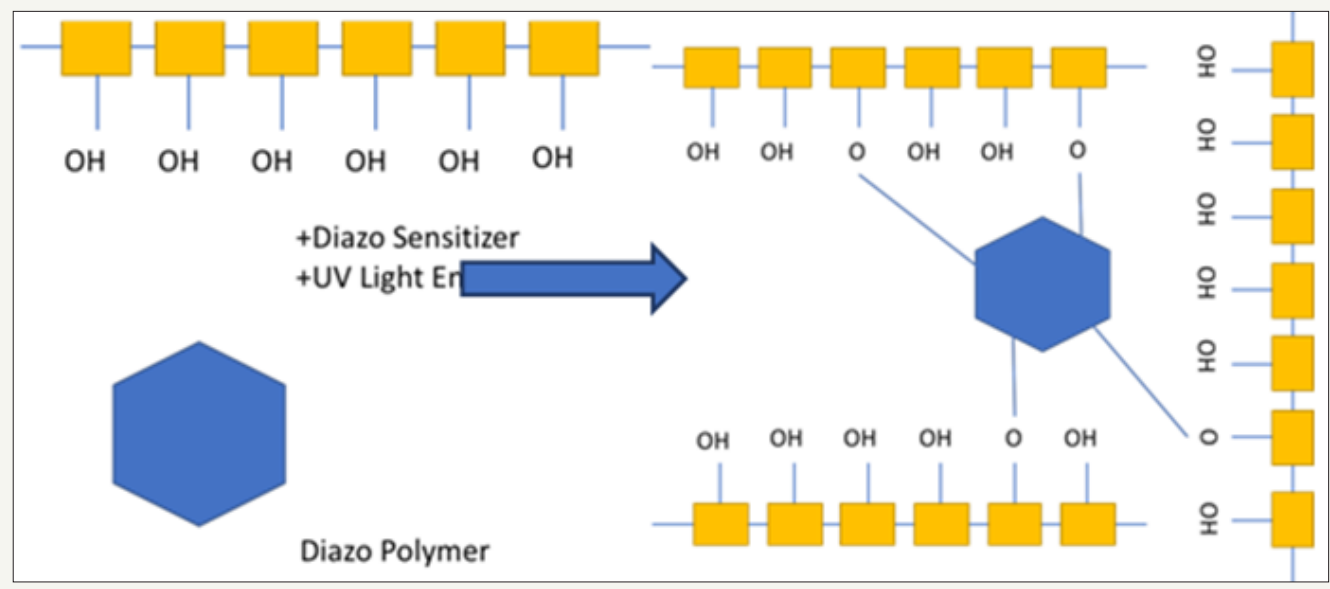

Figure 3: Crosslinking of diazo sensitizer with the photo emulsion [8].

The first screen printing ink was prepared by using $2 \%, 4 \%$ and $6 \%$ concentrations of the natural pigment obtained from Cochineal insect extract mixed with a water based thickening agent which is a mixture of $70-75 \%$ solvent water and $20 \%$ High Solid Acrylics (HSA). The second ink was created by using $2 \%, 4 \%$ and
$6 \%$ concentrations of the Cochineal natural pigment mixed with the HSA water based thickening agent with $10 \%$ stannous chloride (wt./wt.) of the fabric. The inks were mixed with the help of high shear Nano mixer stirrer at 4000rpm as shown in Figure 4.Thus, two types of printing ink were prepared by mixing the Cochineal 
pigment with a water-based binder, with or without the stannous chloride mordant as shown in Figure 5. The mordant was also used in two different ways. In one method, the mordant was mixed directly with the printing ink, whereas in the other, the fabric was soaked in heated stannous chloride solution for 60 minutes.
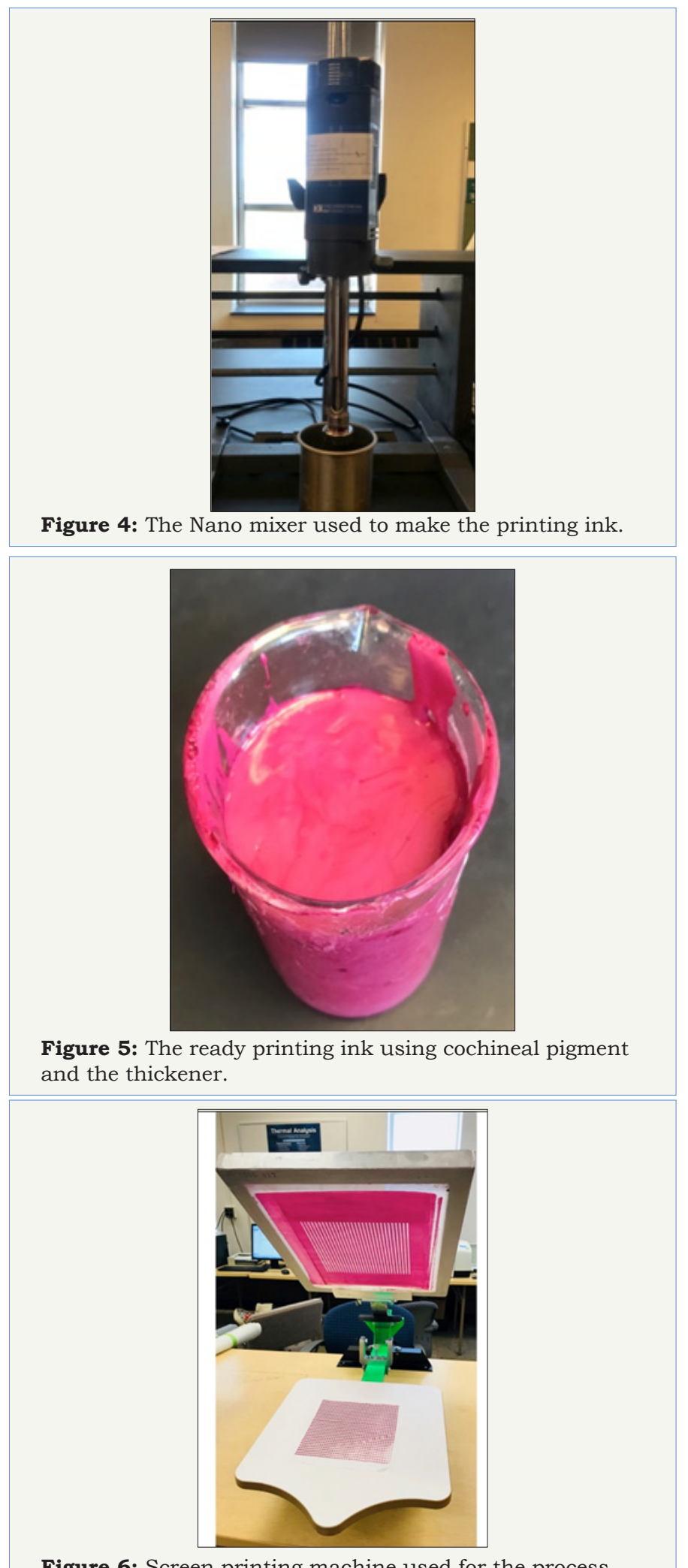

Figure 6: Screen printing machine used for the process.
For printing, a scoured and bleached $100 \%$ cotton fabric was used. The fabric used was a plain weave of $70 \times 70$ (ends/inch and picks/inch) construction and 24 cotton count, weighing 3.60z/sq. yd. The fabric was then printed on a lab screen printing machine as shown in Figure 6, using prepared dyes with or without mordant and also in the fabric presoaked with the mordant. During the printing process, it was made sure that a constant pressure was applied, maintaining a 450 angle with the squeegee so that the ink was applied evenly as shown in Figure 7.

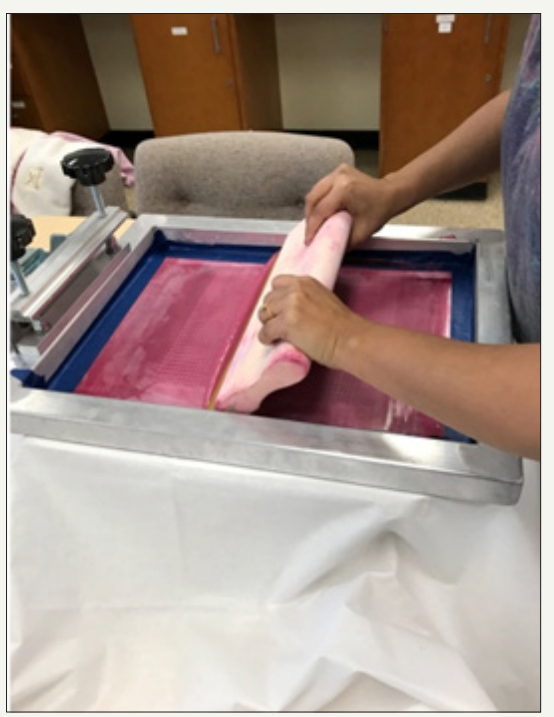

Figure 7: The fabric printed with squeegee using the prepared screen.

The printed fabrics were cured at 150 oC and 160 oC for 3 minutes as per recommended industry standards. The ink used crosslinks with the fiber of the fabric producing strong bonding, making the print color permanent and highly durable.

\section{Test and Evaluation}

\section{Color measurements}

The color values of the printed samples were measured by the CIELAB scale in the spectrophotometer. Also, the color strength test of the printed fabric was performed using a hunter lab color eye spectrophotometer. The color depth was measured by determining the $\mathrm{K} / \mathrm{S}$ value.

\section{$K / S=(1-R) 2 / 2 R$}

$\mathrm{R}=$ Degree of reflectance

$\mathrm{K}=$ Absorption of light

$\mathrm{S}=$ Light scattering

$\mathrm{R}$ is measured at a wavelength of minimum reflectance (maximum absorption)

\section{Rubbing fastness test}

The printed fabrics were tested for colorfastness to rubbing in a Crock meter using an AATCC Test Method 23 and evaluated with the help of a Gray Scale. 


\section{Wash fastness measurements}

The wash fastness of the print was measured by determining the color depth indicator $(\mathrm{K} / \mathrm{S})$ before and after washing the printed fabric. The measurements were obtained using a Hunter Lab Spectrophotometer. Washing was performed in a washing machine (Frigidaire Heavy Duty Washing Machine) using a delicate cycle.

\section{Results and Discussions}

\section{Color measurements}

The $\mathrm{L}, \mathrm{a}, \mathrm{b}$ values of the spectrophotometer exhibited variations when the print pigment concentrations $(2 \%, 4 \%, 6 \%)$ were altered. Moreover, these variations in spectrophotometer values were observed during the change in the curing temperatures from $150 \mathrm{oC}$ to $160 \mathrm{oC}$. The lightness of the color, that is, the ' $L$ ' value decreased with the increase of pigment concentration as expected. The ' $a$ ' value became less red and moved towards green with increase in pigment concentration and 'b' value did not show any trend as can be seen in Table 1 . The color strength or the dye depth measured by the $\mathrm{K} / \mathrm{S}$ value also increased with the increase of the pigment concentration in the ink as expected. Also, the $\mathrm{K} / \mathrm{S}$ value was higher for the print cured at $1600 \mathrm{C}$ than the print cured at $1500 \mathrm{C}$ as shown in Table 1. This occurred as, during the curing process, there was a better dye attachment at elevated temperatures because the crosslinking activity of the dye binder (HSA solvent) was increased at the elevated temperatures. The spectrum for the color values printed at $2 \%, 4 \%$ and $6 \%$ concentration without mordant and cured at 150 oC and 160 oC are shown in Figure 8.

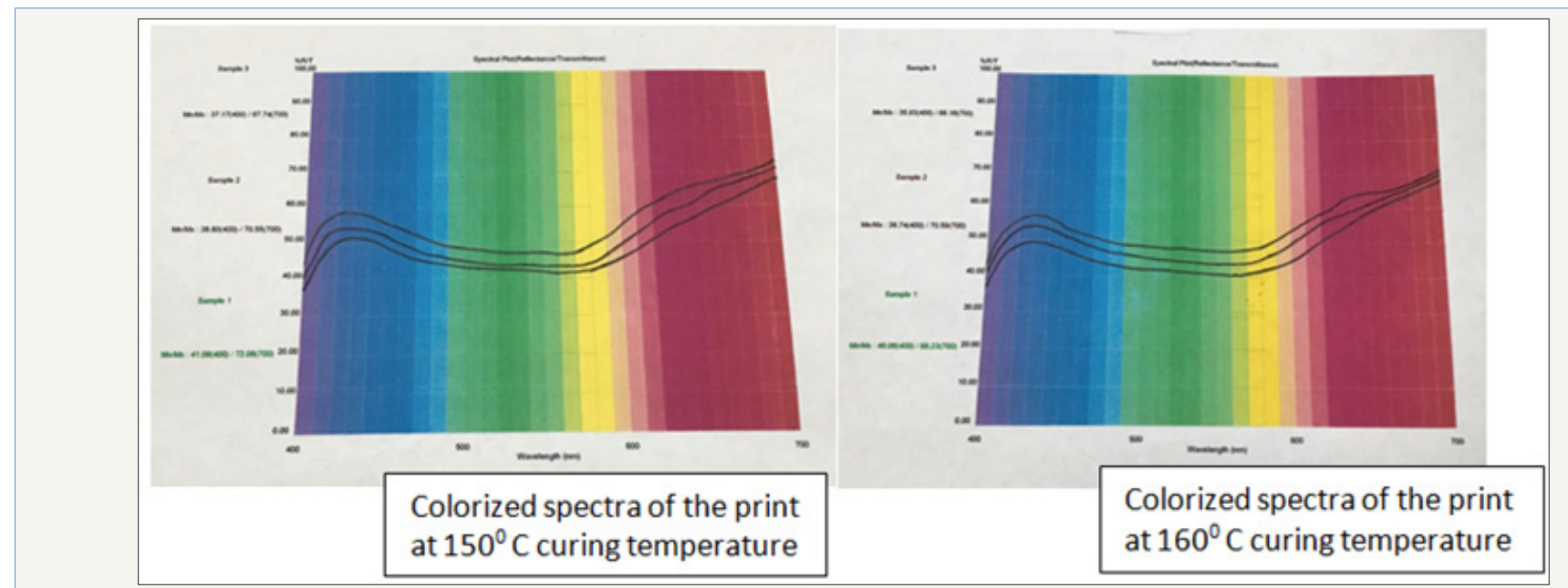

Figure 8: The spectrum of the color values of the printed samples created by $2 \%, 4 \%$ and $6 \%$ dye concentration cured at 150 oC and 160 oC.

Table 1: Color value measurements of the printed samples.

\begin{tabular}{|c|c|c|c|c|c|c|c|c|}
\hline & \multicolumn{3}{|c|}{ Ink Cured @ 150 0C } & \multicolumn{4}{c|}{ Ink Cured @ 160 0C } \\
\hline & $\mathrm{L}$ & $\mathrm{a}$ & $\mathrm{b}$ & $\mathrm{K} / \mathrm{S}$ & $\mathrm{L}$ & $\mathrm{a}$ & $\mathrm{b}$ & $\mathrm{K} / \mathrm{S}$ \\
\hline 2\% Conc. & 76.18 & 9.86 & -4.68 & 1.25 & 75.94 & 7.90 & -3.75 & 1.28 \\
\hline 4\% Conc. & 73.48 & 9.55 & -5.20 & 1.42 & 73.73 & 8.79 & -4.45 & 1.45 \\
\hline 6\% Conc. & 72.13 & 7.49 & -4.91 & 1.62 & 71.41 & 7.97 & -4.28 & 1.75 \\
\hline 6\% Conc. + Tin Mordant & 73.03 & 6.31 & -3.85 & 1.51 & 72.20 & 6.47 & -3.43 & 1.63 \\
\hline 6\% Conc. + Fabric soaked in Tin Mordant & 73.77 & 4.92 & -0.47 & 1.43 & 73.12 & 6.44 & -0.02 & 1.56 \\
\hline
\end{tabular}

\section{Rubbing fastness test}

Table 2: Gray scale rating of the printed fabrics after crocking test.

\begin{tabular}{|c|c|c|c|}
\hline Ink Cured @ 150 0C & Gray Scale Rating & Ink Cured @ 160 0C & Gray Scale Rating \\
\hline $2 \%$ Conc. & 4.5 & $2 \%$ Conc. & 5 \\
\hline $4 \%$ Conc. & 4.5 & $4 \%$ Conc. & 5 \\
\hline $6 \%$ Conc. & 5 & $6 \%$ Conc. & 5 \\
\hline $6 \%$ Conc. + Tin Mordant & 5 & $6 \%$ Conc. + Fabric soaked in Tin Mordant & 5 \\
\hline
\end{tabular}


The printed fabrics produced a rubbing colorfastness as par Gray Scale rating ranging from 4.5 to 5 as shown in Table 2

\section{Wash fastness measurements}

The wash fastness test showed a considerable color loss after washing the printed samples as shown in Figure 9.

The wash fastness data showed a considerable percentage of $\mathrm{K} / \mathrm{S}$ value loss after washing the printed samples as shown in Table 3. The K/S value loss was lower for the print cured at 160
oC than the print cured at $150 \mathrm{oC}$. The decreases in $\mathrm{K} / \mathrm{S}$ value are depicted in a bar chart when the mordanting conditions and curing temperatures were altered as shown in Figure 10.

After plotting the \% $\mathrm{K} / \mathrm{S}$ loss values in a graph, it was clear that the prints cured at $160 \mathrm{oC}$ had much better performance than the prints cured in 1500C. Also, the method where the fabric was soaked in the mordant before printing had the lowest dye depth loss percentage after washing, which was $13 \%$ as a result of better binding of the dye with the fabric as shown in Figure 10.

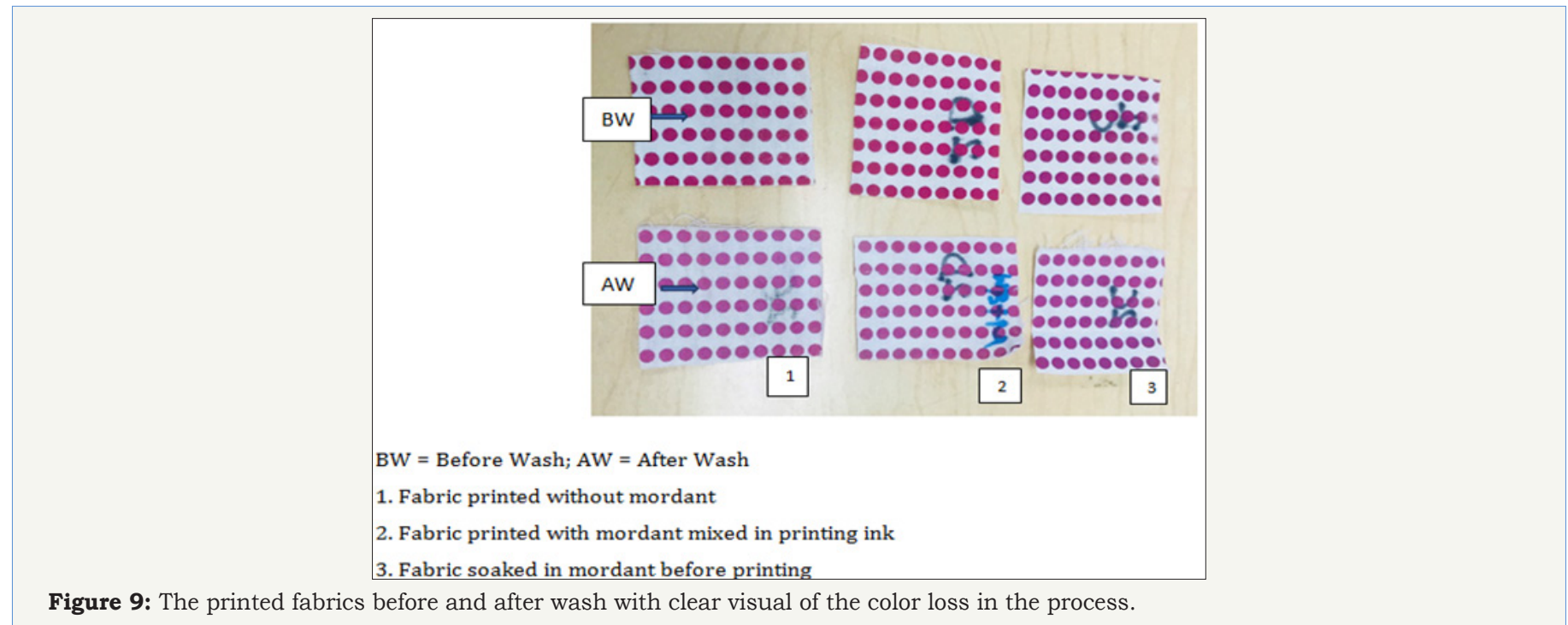

Figure 9: The printed fabrics before and after wash with clear visual of the color loss in the process.

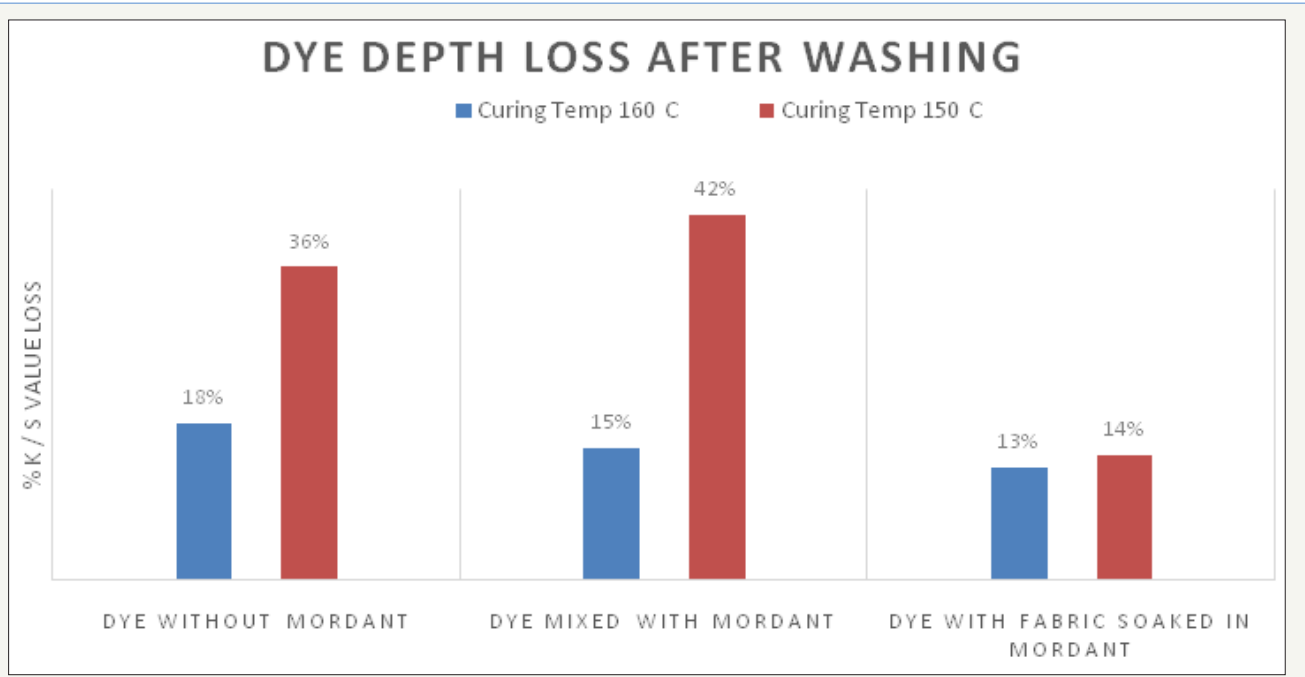

Figure 10: The K/S percentage loss for the printed fabrics in bar graph.

Table 3: Wash fastness data with loss of $\mathrm{K} / \mathrm{S}$ value after washing the printed sample.

\begin{tabular}{|c|c|c|c|c|c|c|}
\hline Curing Temperature & \multicolumn{2}{|c|}{$\mathbf{1 5 0}$ 0c } & \% K/S Loss & \multicolumn{2}{|c|}{$\mathbf{1 6 0}$ 0c } & BW $/ \mathbf{S}$ Loss \\
\hline & BW & AW & & 1.75 & 1.48 & $18 \%$ \\
\hline 6\% Conc. & 1.62 & 1.19 & $36 \%$ & 1.63 & 1.31 & $15.2 \%$ \\
\hline 6\% Conc. + Tin Mordant & 1.51 & 1.06 & $42 \%$ & 1.56 & 1.38 & $13 \%$ \\
\hline
\end{tabular}




\section{Conclusion}

In this study, an attempt was made to improve the colorfastness of natural dyes in screen printing. Screen parameters were optimized in the process, which provided good print quality with acceptable resolution of the print figures. A wash down study was conducted after printing, which showed an approximate $13 \%$ loss in color strength as measured on a Spectrophotometer using K/S values of the printed samples. This was a very promising result for a natural dye and quite at par with some synthetic direct dyes. As found in an additional study, direct dye K/S loss was of $10 \%$. With the more appropriate selection of mordant, the wash fastness could be improved further.

\section{References}

1. Wikipedia/Cochineal.

2. Gabriela A, Graciela MLRA, German CR, Guillermo GS (2010) Cotton fabric dyeing with cochineal extract: influence of mordant concentration. Coloration Technology 127(1): 39-46.
3. Eva Baldaro (2011) Enzymatic improvement of guar-based thickener for better quality silk printing. Coloration Technology 128(4): 315-322.

4. Akemi Yasukawa (2017) Dyeing Silk and cotton fabric using natural blackcurrants. Textile Research Journal 87(19).

5. Sudha B, Rupali G (2016) Screen printing on silk fabric using natural dye and natural thickening agent. Journal of Textile Science \& Engineering $6: 230$.

6. Dawn L Ellams, Robert MC, Sara R (2013) An approach to sustainable coloration of lyocell fabrics by screen printing using extracts of leaves and bark from eucalyptus. Coloration Technology 130(1): 48-53.

7. Mohammad NK, Muriel R, Stephen GY, Chris C (2013) Surface chemical analysis of the effect of curing conditions on the properties of thermallycured pigment printed poly (lactic acid) fabrics. Dyes and Pigments 103: 168-174.

8. Basic chemistry of photosensitive emulsions. PDS International Limited pp. 1-4.
Creative Commons Attribution 4.0 International License

For possible submissions Click Here

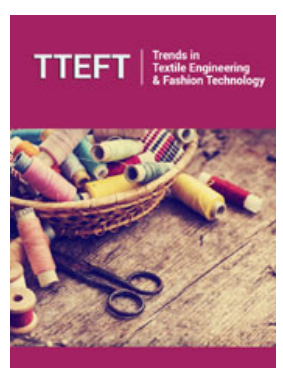

Trends in Textile Engineering \& Fashion Technology

\section{Benefits of Publishing with us}

- High-level peer review and editorial services

- Freely accessible online immediately upon publication

- Authors retain the copyright to their work

- Licensing it under a Creative Commons license

- Visibility through different online platforms 